\title{
Evolution and Review of Modern Eastern Vernacular Buildings
}

\author{
Tian $\mathbf{H u}^{1}$, Wenbin Gong ${ }^{2 *}$ \\ ${ }^{I}$ School of Architecture and Civil Engineering, Xi'an University of Science and Technology, Xi'an, \\ Shaanxi, China \\ ${ }^{2}$ School of Architecture, Southwest Minzu University, Chengdu, Sichuan, China \\ *Corresponding Author.
}

\begin{abstract}
This paper divided the evolution of modern Chinese vernacular architecture (1949-2010) into 3 stages: early exploration, confine and confusion, and modern development, by taking time line as the clue, vernacular characteristics of modern architecture in Xi'an during different phases as the support, and combining literature research and field investigation. On this basis, it reviewed historical background, relevant context and typical features of modern vernacular architecture in Xi'an during different phases, and further concluded the evolution laws and research level of modern Chinese vernacular architecture.
\end{abstract}

Keywords: Modern, Chinese vernacular architecture, Evolution, Typical characteristics

\section{Introduction}

Explorations on the aboriginality of Chinese architecture have gone through difficulties and setbacks since the early twentieth century, and for a long time have been gradually improved in the game between tradition and nationality of architecture and its modernity and globalization. The explorations can be roughly divided into 3 stages, namely early exploration of nationality of Chinese architecture (1900s to 1950s), confine and confusion stage of architectural theories and practices (1960s to 1970s), exploration of aboriginality accompanied with the re-introduction of modern western architectural theories into China (1980s to present). There are different views on the time division of Chinese architectural history, for example, GU Mengchao further divided the first stage into 2 nodes: 1930 and $1953^{[1]}$; ZENG Jian held that after the foundation of the People's Republic of China, explorations on theories of Chinese vernacular architecture apparently belonged to 2 stages: the first 30 years filled with confine, confusion and difficult exploration, and the second 30 years of regressing, exploring and surpassing ${ }^{[2]}$.

\section{Early Exploration of Aboriginality of Chinese Architecture (1900s to 1950s)}

Nationality of Chinese architecture and localization of modern architecture had been explored since western modernism was introduced to China in the early twentieth century. In this period, the explorations centered on national architecture, and "modernization" of traditional architecture, and fell into 3 stages (before the 1950s): church-led exploration on aboriginality of Chinese architecture (1900 to 1920), stage of "Chinese inborn form" (1920 to 1937), and stage of "national form" (1949 to 1959).

2.1 Church-led exploration on aboriginality of Chinese architecture (1900 to 1920)

Western cultures had been introduced to China in an all-around way, and foreign architects had played a leading role in the exploration of aboriginality of Chinese architecture. Buildings in this period were mainly designed in traditional Chinese architectural style, for cultural uses or services, to show the gesture of respecting Chinese

ISSN: 0010-8189

(C) CONVERTER 2021

www.converter-magazine.info 
culture and soothing the emotions of Chinese, and win their recognition of western cultures and even religions. Representatives of this period included American architect H. K. Murphy, and Canadian Harry Hussey, and representative works included Peking Union Medical College, former Furen Catholic University (present College of Adult Education, Beijing Normal Univeristy) (Fig. 1).

\subsection{Stage of "Chinese inborn form" (1920 to 1937)}

Since western culture has invaded Chinese culture seriously, both of them had conflicted fiercely in terms of ideology, culture and life. Againts this background, buildings with "Chinese inborn forms" became an important expression of people's consciousness because their appearances and functions could reflect national consciousness clearly, and they were also regarded as a material means of protecting Chinese self-esteem and strenghtening their confidence. In November 1928, National Government compiled Guidelines for Capital (Nanjing) Planning, and proposed "all buildings in the political areas should apply Chinese inborn forms as far as possible, make the best of the beauty of ancient palaces", "(buildings in commercial areas) should have also Chinese-style decorations in the exeternal side", "(buildings in residential areas) should be designed with Chinese decorations such as pavilion and roof around the external wall". It was the first time that the slogan of "Chinese inborn form" was put forward. In this period, many talented architects who were both trained with western classical and revivalistic architecture and very familiar with traditional Chinese architecture produced quite many innovative architectural works, for example, LIANG Sicheng, YANG Tingbao, LV Yanzhi, TONG Jun, Murphy, DONG Daqiuiu et al ${ }^{[3]}$. Their representative works included Yenching University (1921), Nanjing Sun Yat-sen Mausoleum (1929), Guangzhou Sun Yat-sen Memorial Hall (1931) etc. (Fig. 2). These works started the "similiarity in form" in the development of aboriginality of Chinese architecture. Such a guideline for architectural design proposed by the Nationalist Government - architecture with Chinese inborn form is generally considered as an obvious political product in the modern architectural field, and also a derivative of the Nationalist Government's cultural policies ${ }^{[4]}$.

The exploration of the aboriginality of Chinese architecture in this period centered on tradition, nationality and modernization, and some scholars pointed out that localization of architecture in the early twentieth century was basically a process of modernization dominated by ideology and nationalism ${ }^{[5]}$. After experiencing several times of officially-launched "revival" of traditional cultures, "big roof" of traditional official buildings in north China became a typical architectural symbol in the exploration of architectural aboriginality in this period.

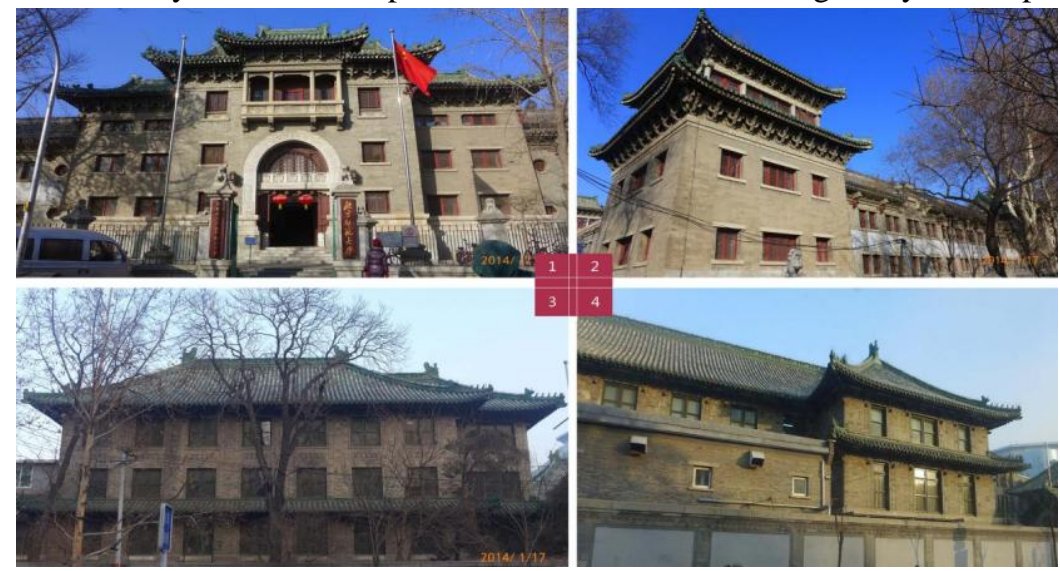

Fig 1: (1)(2) School of adult education, Beijing Normal University; (3)(4)Peking Union Medical College 


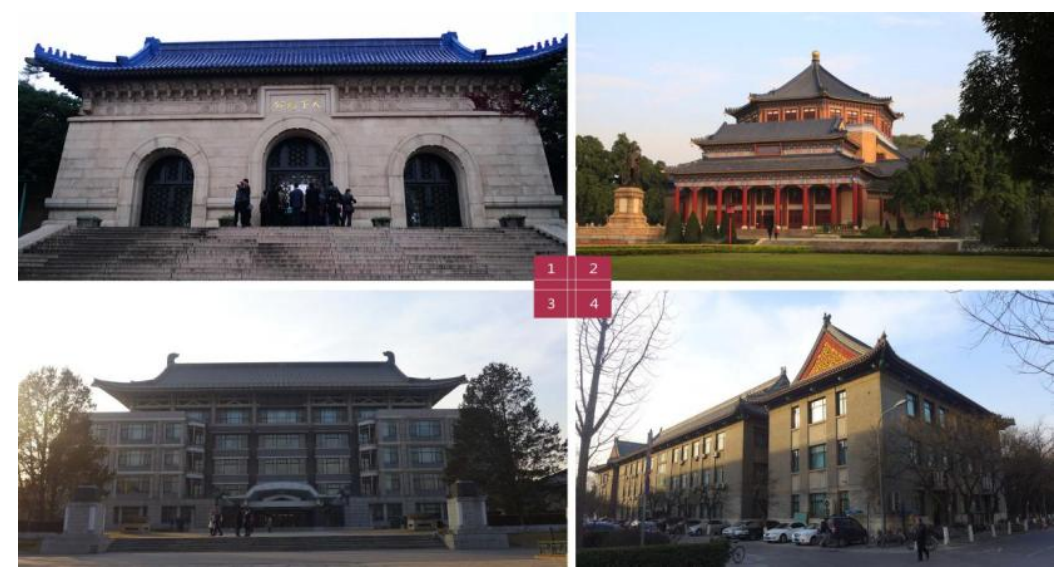

Fig 2: (1) Nanjing Sun Yat-sen mausoleum; (2) Guangzhou Sun Yat-sen memorial hall; (3) Library in Peking University; (4) Classroom building in Peking University

2.3 Stage of "national form" (1949 to 1959)

"National form" is the second trend of architectural thought led by official political consciousness in China (on the basis of previous researches, this stage was divided according to the context and characteristics of Chinese architectural aboriginality in different periods; and there are different views on the division, for example, DENG Qingtan considered 1950-1976 as the stage of "national form"). After the foundation of the People's Republic of China, the former Soviet Union's architectural concept of "socialist contents and national forms" was introduced into the architectural field, which pushed the revitalization of traditional architectural cultures, so this stage also became a typical period in the exploration of aboriginality of Chinese architecture.

Taking the year 1955 as the node, this stage could be further divided into before and after critical revivalism national movement ${ }^{[6]}$. In the first stage, official big-roof building in north China was taken as the prototype ${ }^{[7]}$ (not only the appearance of "big roof" was copied, but also new functions were designed, for instance, bulky apparatuses were placed within the roof, such as elevator equipment room and water tank). In addition, new technologies were applied to produce architectual works with national forms. Typical architects and their representative works included Beijing Friendship Hotel (ZHANG Bo, built in 1954, Fig. 3). In the second stage, concise facade of modern architecture was applied, while traditional Chinese architectural ornaments were used in such parts as door, window and architrave, but decorative patterns of traditional Chinese architectural components were simplified, which also reflected the demand of architectural localization. Typical architects and their works included: Beijing Children's Hospital (HUA Lanhong, FU Yitong, built in 1955) ${ }^{[8]}$ (Fig. 4), office building of Ministry of Works (GONG Deshun, built in 1957) (Fig. 5), Beijing Minzu Hotel (ZHANG Bo, built in 1958) (Fig. $6)$. 

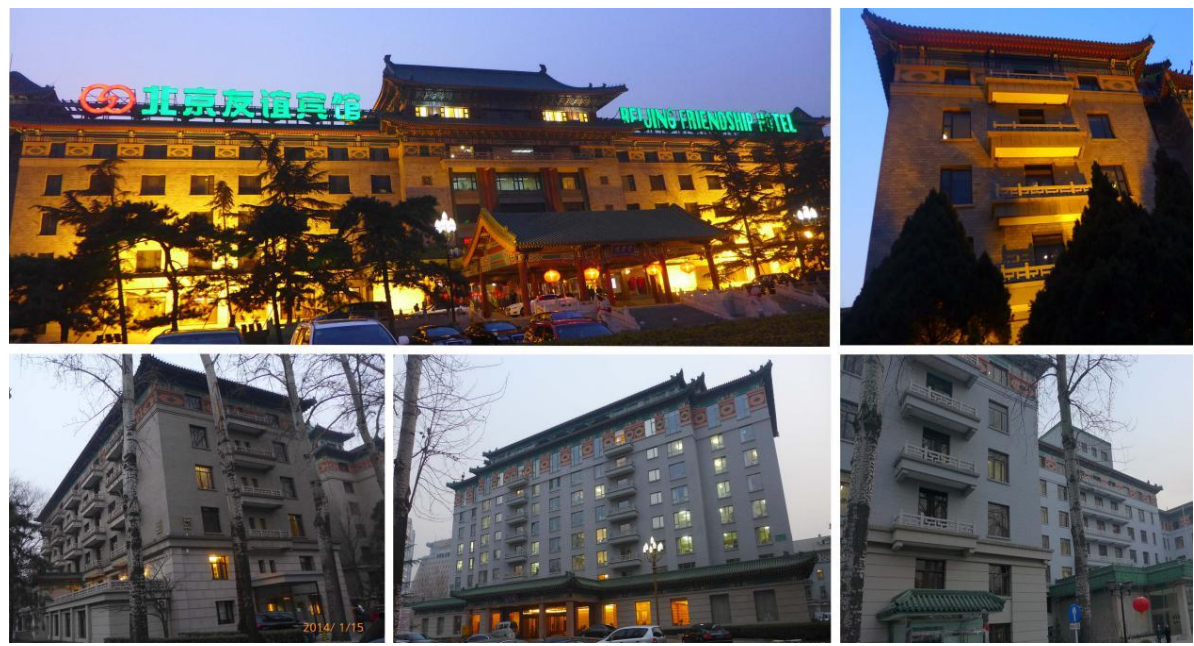

Fig 3: Beijing friendship hotel
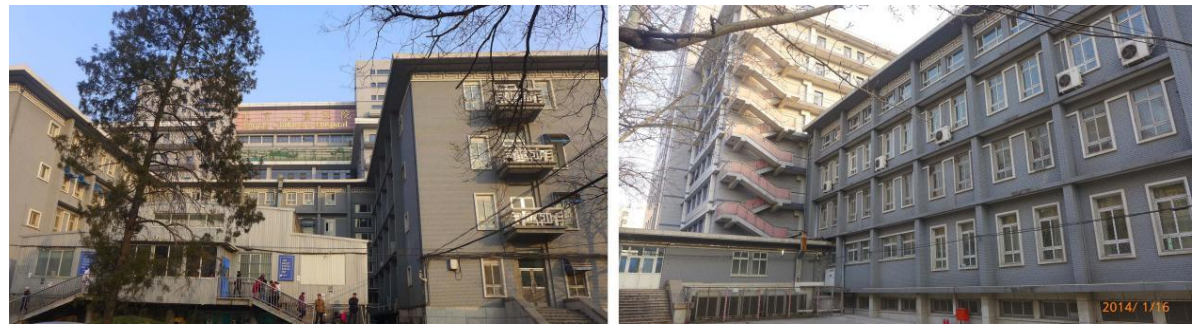

Fig 4: Beijing children's hospital



Fig 5: Office building of ministry of housing and urban-rural construction (former ministry of works)
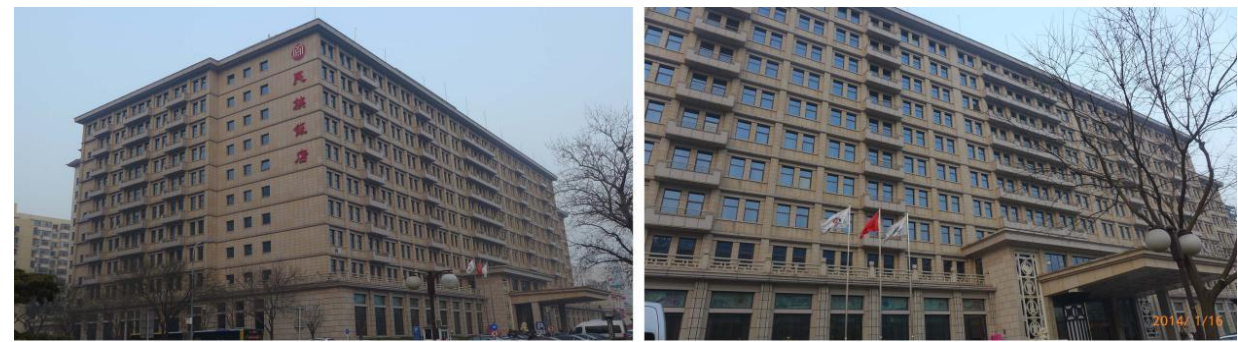

Fig 6: Beijing minzu hotel

Development of Chinese architecture's aboriginality in this stage showed the repeated blending of traditional architectural style and modern architectural style, although ideology played a controlling role in the field of architectural culture ${ }^{[5]}$, the game between tradition and modernity of architecture also existed in the exploration of Chinese architecture's aboriginality, reflecting the complicate attitude towards the relationship between traditional Chinese culture and modern western culture.

ISSN: 0010-8189 


\section{Confine and Confusion Stage of Architectural Theories and Practices (1960s TO 1970s)}

Exploration of architectural aboriginality slowed down for the harsh political and economic environment, and large-scale architectural creations like those in the former stages could hardly be found, practices of pursuing architectural aboriginality were impeded and fell in the confine stage. There were 3 major reasons for the confined exploration of architectural aboriginality: (1) ideologicalization of architectural theories represented by Soviet Union socialist architectural theories; (2) construction policies replaced architectural theories; (3) group design against the background of planned economy ${ }^{[9]}$. In this period, some architects still persisted in their pursuits for architectural aboriginality, and the practices never ceased during the changes of national political and economic situation.

Representative works in this period included National Art Museum of China (DAI Nianci, built in 1962) (Fig.7), Guangzhou Mineral Spring Villa (MO Bozhi, built in 1972), Guangzhou Baiyun Hotel (MO Bozhi, built in 1976). These architectural works showed architects persistence in the extreme political environment, so they had positive significance.
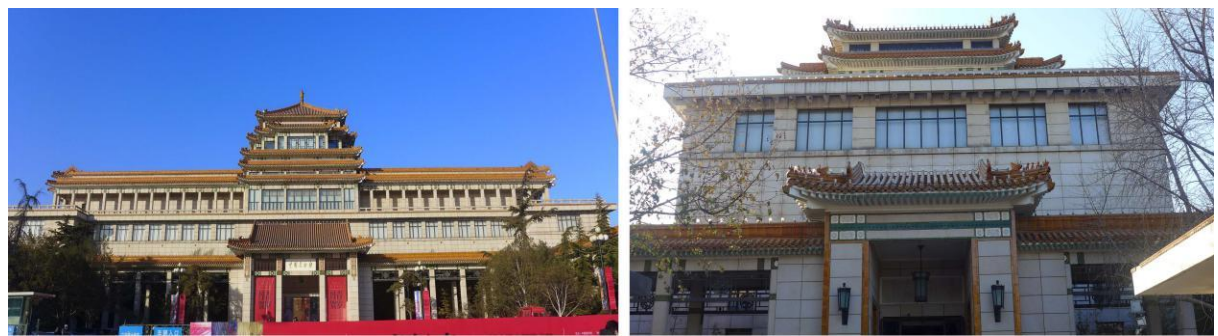

Fig 7: National art museum of China

\section{EXPLORATION OF ABORIGINALITY ACCOMPANIED WITH THE RE-INTRODUCTION OF MODERN WESTERN ARCHITECTURAL THEORIES INTO CHINA (1980s TO PRESENT)}

There have been fewer limitations for architects' creation after the reform and opening up in 1978 for more favorable political and economic environment, and modern western architectual theories have been introduced to China, and domestic researches on architectural aboriginality have been lanuched again. Since the theoretic researches and practices of architectural aboriginality have entered the developing stage, the explorations of architectural aboriginality has shown diversified development trend, which was mainly demonstrated in 4 aspects.

(1) In historical and cultural blocks, forms of traditional buildings were taken to demonstrate the explorations of architectural aboriginality, for example, Queli Hotel in Qufu (Shandong) (DAI Nianci, built in 1986), Three Tang Project in Xi'an (ZHANG Jinqiu, built in 1989). This paper sorted out the revivial of traditional architectural style led by Chinese architects since the twentieth century as Table 1.

Table 1 Development stages of Chinese architecture's aboriginality since the 1950s

\begin{tabular}{|c|c|c|c|c|}
\hline Stage & Phase & $\begin{array}{c}\text { Representatives and } \\
\text { their works }\end{array}$ & $\begin{array}{c}\text { Mainstream contextual } \\
\text { impact }\end{array}$ & Major aboriginal features \\
\hline $\begin{array}{c}\text { First revival of } \\
\text { traditional } \\
\text { architecture }\end{array}$ & 1920s-1930s & $\begin{array}{c}\text { LV Yanzhi (Memorial } \\
\text { Hall in Sun Yat-sen } \\
\text { Mausoleum) }\end{array}$ & $\begin{array}{c}\text { Policies of 'China's } \\
\text { inborn style) promoted } \\
\text { by Nationalist } \\
\text { Government }\end{array}$ & $\begin{array}{c}\text { The large roof form of } \\
\text { northern official architecture }\end{array}$ \\
\hline $\begin{array}{c}\text { Second revival of } \\
\text { traditional } \\
\text { architecture (socialist } \\
\text { contents and national } \\
\text { forms) }\end{array}$ & Early 1950s & $\begin{array}{c}\text { ZHANG Kaiji, ZHANG } \\
\text { Bo (Beijing Friendship } \\
\text { Hotel) }\end{array}$ & $\begin{array}{c}\text { Modernism } \\
\text { architecture was } \\
\text { criticized, Soviet } \\
\text { Union style and } \\
\text { national architectural } \\
\text { forms prevailed }\end{array}$ & $\begin{array}{c}\text { Chinese traditional } \\
\text { roof: big roof, Dougong, etc }\end{array}$ \\
\hline
\end{tabular}




\begin{tabular}{|c|c|c|c|c|}
\hline $\begin{array}{c}\text { Third revival of } \\
\text { traditional } \\
\text { architecture }\end{array}$ & Since 1980s & $\begin{array}{c}\text { Influenced by } \\
\text { diversified concepts } \\
\text { and regional history } \\
\text { and culture in the early } \\
\text { Reform and Opening } \\
\text { Up }\end{array}$ & $\begin{array}{c}\text { Chinese traditional } \\
\text { architectural form symbol: big } \\
\text { roof: big roof, Doug. ong, etc }\end{array}$ \\
\hline
\end{tabular}

(2) The tendency of being demonstrated in abstract symbols of traditional cultures. Typical works included Beijing Xiangshan Hotel (BEI Yuming, built in 1982), Shanghai Fangta Garden (FENG Jizhong, built in 1987).

(3) The tendency of exploring traditional cultural connotations and expressions. Typical works included Ningbo Museum (WANG Shu, built in 2008), Commune by the Great Wall (ZHANG Yonghe, CUI Kai et al., built in 2006).

(4) The tendency of exploring environmental adaptability of buildings according to natural, geographical and climatic conditions in different regions. In addition, the research scope expanded from urban architecture to countryside architecture, more efforts were devoted in exploring wisdoms in rural buildings.

In general, domestic explorations of architectural aboriginality have merged with the development trend of world architecture, showing Chinese characteristics and diversity.

\section{Review of Domestic Researches on Architectural Aboriginality}

Through reviewing domestic explorations on architectural aboriginality, it was found that researches in different periods focused on varying aspects (Table 2). In the 1950s to 1960s, the explorations were dominated by "nationality"; from the late 1970s to 1980s, more attention was given to rethinking on the "form similarity" of architecture, and the argument between tradition and modernity of architecture; in the 1990s, techniques of architectural creations were more discussed because of the introduction of western post-modernism, semiology and typology, thus researches on Chinese architectural aboriginality focused more on symbolization; since the twenty-first century, the explorations focused more on spatial needs and intentions, "similarity in both form and spirit", and became "diversified" for the dominance of phenomenology and tectonics in regional development.

Table 2 Contents of researches on aboriginality of Chinese architecture

\begin{tabular}{|c|c|c|}
\hline No. & Phase & Characteristics \\
\hline 1 & $1950 \mathrm{~s}-1960 \mathrm{~s}$ & Mainly on nationality of architecture \\
\hline 2 & $1970 \mathrm{~s}-1980 \mathrm{~s}$ & $\begin{array}{c}\text { On nationality, regionality and modernity, and also politicization of } \\
\text { architecture }\end{array}$ \\
\hline 3 & $1990 \mathrm{~s}$ & Introduction and digestion of theories, and practical applications \\
\hline 4 & $21^{\text {st }}$ century to present & $\begin{array}{c}\text { The focus shifts from form to content, the ovearll researches show the } \\
\text { trend of diversity }\end{array}$ \\
\hline
\end{tabular}

In general, practices went first than theories in domestic researches on architectural aboriginality. Theoretical researches shifted the focus from nationality and tradition to the coexistence of globality, modernity, nationality and tradition. Particularly in the past 15 years, domestic researches on architectural aboriginality have attached more importance to the exploration of traditional cultures, and the techniques of showing architectural aboriginality have been enriched greatly. Although the overall framework has been gradually established, theoretical researches on architectural aboriginality showing the tendency of changing from inheritance of western architectural theories to systematic analysis and rational criticism ${ }^{[10]}$. However, the researchers have not touched upon regional practices, particularly in the hinterland, current researches on architectural aboriginality were inadequate in terms of both quantity and content, and could be further expanded.

ISSN: 0010-8189

(C) CONVERTER 2021

www.converter-magazine.info 


\section{Acknowledgements}

Sponsored by Cultivation Foundation of Xi'an University of Science and Technology (201640).

\section{References}

[1] M.C. Gu, "Thinking on "Three Centuries" of modern architecture," Architectural Journal, no. 2, pp. $54-55,2002$.

[2] J. Zeng, X.R. Luo, "From confine to open, from conservation to innovation-60-year explorations of Chinese architectural theories," Architectural Journal, no. 10, pp. 5-9, 2009.

[3] L.Y. Zhao, "Review on "national form" creations of Chinese architecture," Journal of Xi'an University of Architecture \& Technology (Natural Science Edition), no. 9, pp. 10, 1981.

[4] Q.T. Deng, "Research outlines of modern Chinese architecture," Beijing: China Architecture and Building Press, 2008.

[5] X.Y. Chen, D.K. Zhong, "Local buildings and suitable technologies," Beijing: China Architecture and Building Press, 2007.

[6] T.W. Zhang, "The Third Wave" in Chinese architectural field: innovation of concept and architecture. Architect, no. 28, pp. 1, 2009.

[7] Y.G. Qin, "China-style expression in modern Chinese architecture," Architectural Journal, no. 6, pp. 20-23, 2004.

[8] D.N. Zou, "Progress of architecture in turbulance: the first 30 years after the foundation of PRC," Architectural Journal, no. 9, pp. 40, 2009.

[9] Q.N. Zhang, Z.G. Zhang, "Architectural theories in modern Chinese cultural context," Beijing: China Architecture and Building Press, 2008.

[10] J. Shan, "Aboriginality of architecture and city: research on regional architecture based on human settlement concept," Beijing: China Architecture and Building Press, 2010. 